\title{
Continuous-flow isotope ratio mass spectrometry method for carbon and hydrogen isotope measurements on atmospheric methane
}

\author{
M. Brass and T. Röckmann \\ Institute for Marine and Atmospheric research Utrecht, Utrecht University, Utrecht, The Netherlands \\ Received: 13 April 2010 - Published in Atmos. Meas. Tech. Discuss.: 28 May 2010 \\ Revised: 29 November 2010 - Accepted: 7 December 2010 - Published: 14 December 2010
}

\begin{abstract}
We describe a continuous-flow isotope ratio mass spectrometry (CF-IRMS) technique for high-precision $\delta \mathrm{D}$ and $\delta^{13} \mathrm{C}$ measurements of atmospheric methane on $40 \mathrm{~mL}$ air samples. $\mathrm{CH}_{4}$ is separated from other air components by utilizing purely physical processes based on temperature, time and mechanical valve switching. Chemical agents are avoided. Trace amounts of interfering compounds can be separated by gas chromatography after pre-concentration of the $\mathrm{CH}_{4}$ sample. The purified sample is then either combusted to $\mathrm{CO}_{2}$ or pyrolyzed to $\mathrm{H}_{2}$ for stable isotope measurement. Apart from connecting samples and refilling liquid nitrogen as coolant the system is fully automated and allows an unobserved, continuous analysis of samples. The analytical system has been used for analysis of air samples with $\mathrm{CH}_{4}$ mixing ratios between $\sim 100$ and $\sim 10000 \mathrm{ppb}$, for higher mixing ratios samples usually have to be diluted.
\end{abstract}

\section{Introduction}

Methane $\left(\mathrm{CH}_{4}\right)$ is an important anthropogenic greenhouse gas and its concentration has increased since pre-industrial times by $>150 \%$ (Etheridge et al., 1998; MacFarling Meure et al., 2006). Due to its relatively long lifetime in the troposphere of 8 to 9 years (Prinn et al., 1995; Karlsdottir and Isaksen, 2000; Dentener et al., 2003), it has a rather uniform distribution and small seasonal cycle (Rasmussen and Khalil, 1981; Steele et al., 1992; Dlugokencky et al., 1997), which means that its global burden, and changes thereof in time, can be determined with great precision from current measurement networks. However, the respective contributions to these changes from the various sources and sinks are only

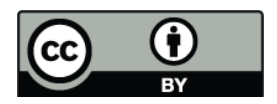

Correspondence to: T. Röckmann (t.roeckmann@uu.nl) poorly constrained (Forster et al., 2007). For example, there is still no general consensus on which processes led to the decrease of the global $\mathrm{CH}_{4}$ growth rate in the 1990s, the period of stable concentrations since 2000, and the recovery of the increase again since 2007 (Dlugokencky et al., 1994, 1998, 2001, 2003, 2009). The spatial distribution of $\mathrm{CH}_{4}$ as measured from ground stations or from space (Frankenberg et al., 2008) can be used to localize emissions using inverse modeling (Meirink et al., 2008; Bergamaschi et al., 2009).

Isotope measurements are well suited to provide additional information since different sources emit $\mathrm{CH}_{4}$ with a characteristic and in many cases distinct isotopic composition (Lowe et al., 1994; Bergamaschi et al., 1998, 2000; Quay et al., 1999; Miller et al., 2002; Brenninkmeijer et al., 2003; Tarasova et al., 2006). For example, $\mathrm{CH}_{4}$ from biological processes like boreal and tropical wetlands, rice cultivation, ruminants and waste decomposition is usually strongly depleted in both ${ }^{13} \mathrm{C}$ and $\mathrm{D}\left(\delta^{13} \mathrm{C} \sim-60 \%\right.$ o, $\delta \mathrm{D} \sim-300 \%$ ), $\mathrm{CH}_{4}$ from thermogenic processes (natural gas and coal mining) is more enriched in both heavy isotopes $\left(\delta^{13} \mathrm{C} \sim-40 \%\right.$, $\delta \mathrm{D} \sim-150 \%$ ) and $\mathrm{CH}_{4}$ from biomass burning is unusually enriched in ${ }^{13} \mathrm{C}\left(\delta^{13} \mathrm{C} \sim-25 \%\right.$ o, $\delta \mathrm{D} \sim-230 \%$ ) (Quay et al., 1999). $\mathrm{CH}_{4}$ from gas hydrates is depleted in ${ }^{13} \mathrm{C}$ but enriched in $\mathrm{D}\left(\delta^{13} \mathrm{C} \sim-60 \%, \delta \mathrm{D} \sim-200 \%\right.$ o). The isotopic composition of the recently discovered source of $\mathrm{CH}_{4}$ from organic matter (Keppler et al., 2006; McLeod et al., 2008; Vigano et al., 2008, 2009) is actually similar to the values found for microbial formation (Vigano et al., 2009, 2010), although the process itself is abiotic. Thus, isotope analysis yields independent constraints on the relative source contributions to the global methane budget, not only for the present but also for the past atmosphere (Ferretti et al., 2005; Sowers et al., 2005; Schaefer et al., 2006, 2006; Fischer et al., 2008; Mischler et al., 2009; Bock et al., 2010b). However, the measurements are not straightforward and persistent and experimental challenges often limit more widespread use of isotope

Published by Copernicus Publications on behalf of the European Geosciences Union. 


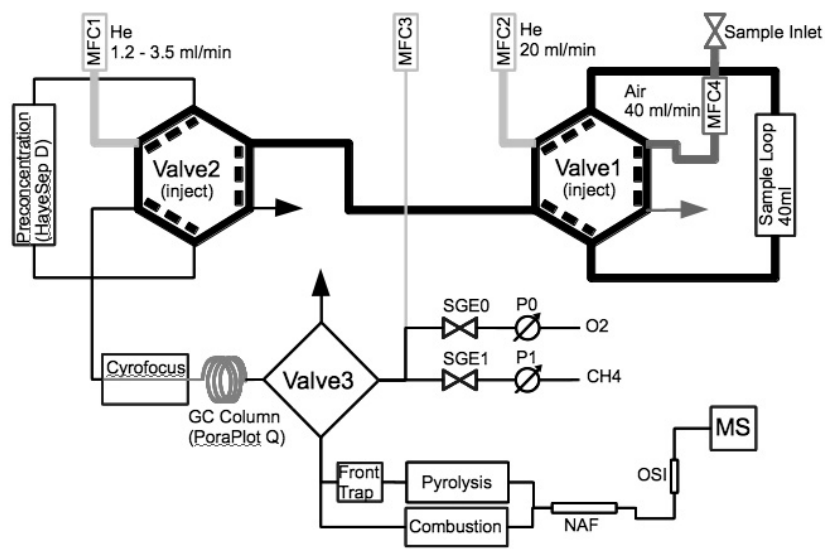

Fig. 1. Scheme of the online methane analysis system: methane from the sample air stored in the sample loop is isolated from other air components by subsequent preconcentration, cryofocussing and gas chromatographic separation. The separated methane is then either combusted to $\mathrm{CO}_{2}$ (for $\delta^{13} \mathrm{C}$ measurement) or pyrolyzed to $\mathrm{H}_{2}$ (for $\delta \mathrm{D}$ measurement) and injected into the isotope ratio mass spectrometer for isotopic analysis. Three high-purity helium flows (MFC1-3), continuously purging the system, are used as inert carrier gas. Additionally, $\mathrm{O}_{2}$ and $\mathrm{CH}_{4}$ are injected through the valves SGE0 and SGE1 to test and condition the conversion ovens (see text for further details). The thick lines represent $1 / 8^{\prime \prime}$ stainless steel tubes and the thin lines are fused-silica capillaries with an inner diameter (i.d.) of $0.43 \mathrm{~mm}$. The capillaries connecting the pyrolysis furnaces have an i.d. of $0.32 \mathrm{~mm}$.

techniques. Here we present a detailed description of a highprecision $\mathrm{CH}_{4}$ isotope system that uses sample amounts of $40 \mathrm{~mL}$ of air. We describe in detail the general setup (chapter 2), but also the peculiar issues related to peak integration (chapter 3) and calibration (chapter 4) that have so far not been discussed in the literature.

\section{The analytical system}

\subsection{Overview}

Figure 1 shows schematically the experimental setup, which is based on the principle developed by (Ricci et al., 1994; Merritt et al., 1995; Sessions et al., 2001a, b) and similar to the systems described by (Miller et al., 2002; Schaefer and Whiticar, 2007; Behrens et al., 2008) for $\delta^{13}$ C, (Bock et al., 2010a) for $\delta \mathrm{D}$ and (Rice et al., 2001) for both stable isotopes. A measurement is performed in seven separate steps: (1) a fixed sample volume (sample loop) is filled with sample air from the inlet system (2) $\mathrm{CH}_{4}$ is pre-concentrated, i.e., separated from the bulk air (3) $\mathrm{CH}_{4}$ is focused in a small volume (4) $\mathrm{CH}_{4}$ is separated gas chromatographically from remaining gas components (5) $\mathrm{CH}_{4}$ is converted to either $\mathrm{CO}_{2}$ or $\mathrm{H}_{2}$ (6) the converted $\mathrm{CH}_{4}$ is injected into the mass spectrometer via an open split interface (7) the molecular ion current ratios are detected by the mass spectrometer and the peak areas evaluated. These steps are performed within $21 \mathrm{~min}$ and will be described in detail in the following subchapters.

The analytical system is permanently purged with helium (purity 5.0, i.e. $99.999 \%$ ) from a central laboratory supply that passed an additional helium purifier (Supelco, catalogue no 2-3801). Three separate flows of He are created from this supply and the flow rates controlled by mass flow controllers (MFC). MFC2 (MKS 1179AX 12C S1BV, $100 \mathrm{sccm}$ ), controls the high flow rate He stream $(20 \mathrm{~mL} / \mathrm{min})$ that carries the sample gas from the sample loop to the preconcentration unit. The low flow rate He stream from MFC1 (MKS 1179AX 11C S1BV S024, $10 \mathrm{sccm}$ ), which typically operates between 0.4 and $1.2 \mathrm{~mL} / \mathrm{min}$, transports the preconcentrated methane sample further through cyrofocus, gas chromatographic (GC) column, conversion oven and NAFION dryer (NAF) to the open split interface (OSI) and into the mass spectrometer (MS). He from MFC3 (MKS 1179AX $51 \mathrm{C} \mathrm{S1BV}, 50 \mathrm{sccm})$ is a multi-purpose purge flow that is used to keep the ovens, the split interface and the mass spectrometer clean while residual gases are vented behind the GC column, and to condition the ovens with He-diluted oxygen (valve SGE0) or methane (valve SGE1). The default flow rate of MFC3 is set to $3.2 \mathrm{ml} / \mathrm{min}$, but the flow rate varies between 0 and $5 \mathrm{~mL} / \mathrm{min}$ depending on the actual purpose.

Three 2-position valves (Valco A46UWM for Valve 1 and 2; Valco A4C4WM for Valve 3) direct the flows through the system. Valve 1 is used to fill the sample loop at $40 \mathrm{~mL} / \mathrm{min}$ with sample air via MFC4 (MKS 1179AX 12C S1BV, 100 sccm) in "load" position and to inject the sample into the preconcentration unit in "inject" position. During this transfer, Valve 2 is in "load" position until the bulk air has been flushed through the unit, and it switches to "inject" to release the preconcentrated $\mathrm{CH}_{4}$ to the cryofocussing unit. Valve 3 is used to selectively transfer only the $\mathrm{CH}_{4}$ peak eluting from the GC column further to the conversion ovens; otherwise the furnaces are flushed with clean He.

\subsection{Sample inlet system}

The sample inlet system has been set up to allow analysis of various types of samples. Air samples that are pressurized to at least 1300 mbar can be analyzed with the automated highpressure (HP) inlet, samples at lower pressure with the manual low-pressure (LP) inlet. The two systems can be manually selected with the hand switch HS1.

\subsubsection{High-pressure inlet}

High-pressure samples are admitted to the sample loop from multiposition valve MULTI1 (Valco, stop end type, SD8UWM) via MFC4 at a flow rate of $40 \mathrm{~mL} \mathrm{~N}_{2} / \mathrm{min}$. After a delay of $\sim 30 \mathrm{~s}$ to purge the transfer line from MFC4 to Valve1 and to establish a steady sample flow, Valve1 is switched to "load" and in standard analyses the sample gas 


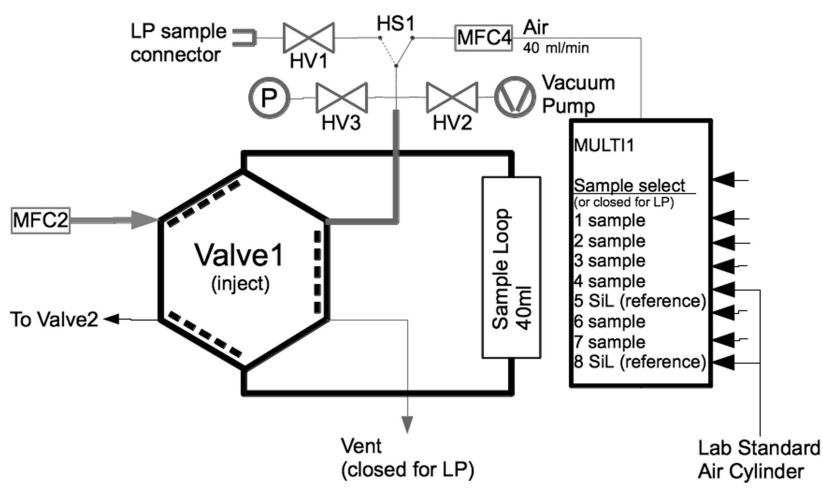

Fig. 2. Detailed scheme of inlet sub system. The inlet sub system can be chosen to either operate automatically on sample containers at high pressure or to analyze containers at low pressure manually. The default position of Valve1 is indicated by dotted lines.

flushes the loop for $90 \mathrm{~s}$. Then, Valve1 is switched back to "inject", the sample flow is stopped by setting MFC4 to flow rate $0 \mathrm{~mL} / \mathrm{min}$, and the sample gas is pushed to the preconcentration unit with the carrier gas He from MFC2. The highpressure inlet system has not shown any detectable memoryeffect when switching between different samples.

\subsubsection{Low pressure inlet}

With the vent capillary at atmospheric pressure, the sample loop can only be filled through the mass flow controller if the absolute pressure of the sample container is above 1300 mbar. To allow sample measurements below this pressure limit, the vent capillary and the multiposition valve are permanently closed, so that the entire inlet system including the sample loop (Valve1 = "load") can be evacuated (Pfeiffer DUO 2.5). The sample air from the LP connector is then expanded to the loop by closing hand-valve HV2 (vacuum pump) and switching (HS1) to the LP connector. After pressure equilibration Valve1 injects the gas to the preconcentration unit and analysis continues as for the HP inlet. After the sample transfer is finished, Valve1 switches back to position "load" and HV2 is reopened to evacuate the inlet for the next sample. An additional pressure sensor (Sensor Technics CTE8001AL0, 0-1 bar abs.) is used to determine the loop pressure and to calculate the methane concentration of the sample from the measured peak area. The loop pressure is continuously recorded when HV3 (pressure meter) is opened. It is necessary to slightly modify the transfer times for the LP inlet compared to the HP inlet because the sample loop is filled to a lower pressure. When injecting the sample, the carrier gas He first needs to fill the loop volume to a comparable pressure level inside.

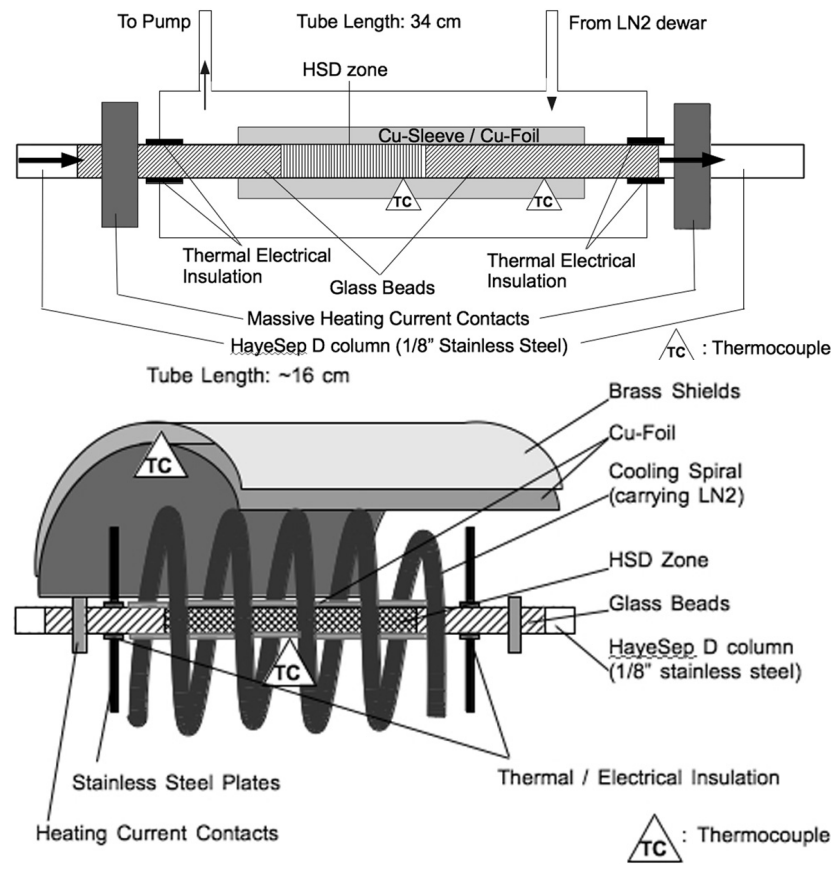

Fig. 3. Top: trap design 1 uses a cold nitrogen atmosphere and the evaporation of liquid nitrogen drops in a chamber built around the HSD tube for cooling. Bottom: trap design 2 uses air as cooling and insulation medium. Cooling the air inside the unit is achieved by pumping liquid nitrogen through a stainless steel spiral that is coiled around the HSD column.

\subsection{Preconcentration}

The heart of the preconcentration unit consists of a $1 / 8^{\prime \prime}$ stainless steel tube filled in the centre with a $6 \mathrm{~cm}$ column of HayeSep D (HSD; 80/100 mesh, Alltech Associates, Inc.), secured from both sides with glass beads and glass wool. When this column is cooled down to temperatures around $-130{ }^{\circ} \mathrm{C}$ it traps and keeps $\mathrm{CH}_{4}$ from the sample air for at least $20 \mathrm{~min}$. Most of the $\mathrm{N}_{2}$ and $\mathrm{O}_{2}$ in the sample air pass the HSD column, thus separation from the bulk components is largely achieved in the trapping phase. In the standard analysis the trapped methane is purged for $6 \mathrm{~min}$. Longer purge times do not significantly improve the reproducibility of the $\delta$-values, which is repeatedly checked by extending the purge time for $2 \mathrm{~min}$. When most of the permanent gases have been flushed out (after at least 4 min purge time), $\mathrm{CH}_{4}$ is released by stopping the cooling pump and heating up the $\mathrm{HSD}$ column to $-85^{\circ} \mathrm{C}$. At this temperature $\mathrm{CO}_{2}$ and $\mathrm{H}_{2} \mathrm{O}$ are still retained on the column $\left(\mathrm{CO}_{2}\right.$ only elutes above $-35^{\circ} \mathrm{C}$ ). Thus, by selecting appropriate temperature bands and valve switching, the system separates $\mathrm{CH}_{4}$ from most of the $\mathrm{N}_{2}, \mathrm{O}_{2}, \mathrm{CO}_{2}, \mathrm{H}_{2} \mathrm{O}$ and other condensable gases without any need of additional chemicals or separation columns already in the preconcentration phase of the run. After methane has been completely transferred to the cryofocus by the MFC1 flow at $1.2 \mathrm{~mL} / \mathrm{min}$, Valve2 is switched 
back to the "load" position and the helium flow from MFC2 $(20 \mathrm{~mL} / \mathrm{min}$ ) flushes out remaining carbon dioxide, water and other condensable compounds, while the unit is heated up to $+70{ }^{\circ} \mathrm{C}$ for $380 \mathrm{~s}$. Higher temperatures for the regular heat out shorten the HayeSep D lifetime. Only occasionally the HSD unit is heated up to $150^{\circ} \mathrm{C}$ for several hours for cleaning. The column should be replaced after 1 year.

It is crucial that the system can be stabilized at different temperatures with only small temperature gradients in the unit. Figure $3 \mathrm{a}$ and $\mathrm{b}$ illustrate the concept of two developed HSD units. The two units use liquid nitrogen for cooling and achieve the required temperature by appropriate counter heating $(\mathrm{AC}, 2 \mathrm{~V})$. The electrical resistance of the stainless steel tube is used for heating and therefore only two contacts at the inlet and outlet of the column are needed. The HSD column is fixed to and electrically isolated from the surrounding unit using Teflon ferrules. Using a low heating current ensures that temperature gradients along the tube are small. In the final design the temperature deviations have been minimized, although a hot spot still develops halfway between the contacts (if both contact resistances are similar) and temperature gets lower towards the ends of the tube.

Trap 1 is based on the design presented by (Miller et al., 2002). The trap is cooled by sucking liquid nitrogen from a Dewar through the preconcentration unit (Fig. 3a). When the connecting lines are cooled down, drops of liquid nitrogen enter the unit and due to their evaporation in the trap the target temperature is reached quite fast $(2-4 \mathrm{~min})$. On the other hand, temperatures down to $-185^{\circ} \mathrm{C}$ are reached at the liquid nitrogen inlet and volatile components like $\mathrm{N}_{2}$ or $\mathrm{O}_{2}$ are retained at this point. Counter heating helps to stabilize the HSD column at higher temperature, but in this design this leads to an inhomogeneous temperature distribution (cold spot at nitrogen inlet overlaid by hotspot in the middle of the tube). Placing an additional $\mathrm{Cu}$-sleeve around the steel tube diminishes the effect since it ensures a fast temperature equilibration and leads to a nearly constant temperature in the HayeSep zone. Still, the strong required counter heating wastes liquid nitrogen and limits the time that the system can operate unattended from a single Dewar. The inefficient use of nitrogen limiting the operational time and the difficult temperature control due to the inhomogeneous temperature distribution were the main reasons to further develop design 2 , although the measurement results were not affected.

Instead of using the direct contact of liquid nitrogen to the HSD tube, in trap design 2 the nitrogen stream is processed through a separate $1 / 8^{\prime \prime}$ stainless steel spiral surrounding the HSD column (Fig. 3b). Enclosed air is used as cooling and at the same time thermal insulation medium. The cooling spiral is wrapped in a $\mathrm{Cu}$-foil and a brass shield that form a cylinder. Two metal plates at the ends close the cooling volume and additionally fix the position of the HSD column relative to the cooling spiral. The HSD column itself must be thermally (and electrically) insulated against the metal plates by plastics that can be used over the required temperature range reaching from $-185^{\circ} \mathrm{C}$ to $+150^{\circ} \mathrm{C}$. The whole unit is enclosed in Styrofoam, which needs to be removed when the unit is heated to high temperature $\left(T>70^{\circ} \mathrm{C}\right)$ for cleaning. In this design we use a variable vacuum pump (VacuuBrand Vario MD1, up to $1.31 / \mathrm{min}$ ) that allows adjusting the liquid nitrogen usage to actual needs. By avoiding the direct contact with liquid nitrogen much lower currents are needed for counter heating. Instead of a thick $\mathrm{Cu}$-sleeve a thin $\mathrm{Cu}$-foil is wrapped around the HSD column. The glue and the enclosed air add an insulation layer between HSD column and copper. This insulation, the reduced amount of copper and the lower heating current allow a more efficient heating. Therefore, the whole unit is heated less and remains colder between analyses, so that for subsequent measurements the cooling speeds up. However, in general the cooling through air needs more time (6-9 $\min )$ than in the case of a direct liquid nitrogen contact.

Temperatures are measured with type $K$ thermocouples. In the first design they were point welded to the outside of the HSD column through an opening in the Cu-Sleeve. In design 2 they are fixed on the $\mathrm{Cu}$ foil using a silver covered copper wire, isolated against the foil and surrounding air with Kapton tape (Scotch 3M electrical tape 92). The readouts of the thermocouples are galvanically separated, so that heating does not interfere with the temperature measurement. The decreases in heating and cooling power lead to a lower temperature gradient, which allows more precise regulation.

\subsection{Cryofocussing}

The release of $\mathrm{CH}_{4}$ from the HSD unit takes about 2 to $6 \mathrm{~min}$, so without an additional focusing the eluted peak is far too broad and its amplitude too small for an isotope ratio measurement. Furthermore, the separation in the HSD unit is not perfect, so that small remaining amounts of $\mathrm{O}_{2}, \mathrm{~N}_{2}$ and $\mathrm{CO}_{2}$ can harm conditioning of the furnaces or cause interferences in the mass spectrometer. Therefore, the $\mathrm{CH}_{4}$ sample is trapped a second time on the head of a GC column to focus it to a sharp peak and the remaining components are gas chromatographically separated.

The focus unit is a trap of design 1 (Fig. 3a), i.e. liquid nitrogen from a Dewar is pumped through a volume containing the column with a vacuum pump (VacuuBrand MD1, $1.0 \mathrm{~m}^{3} / \mathrm{h}$ ). The GC column (PoraPLOT Q, see Sect. 2.5) is contained in a $1 / 16^{\prime \prime}$ stainless steel tube $(24 \mathrm{~cm}$ length) wrapped in $\mathrm{Cu}$-foil with three thermocouples attached to the head, mid and end. The temperature is regulated at the central position and the two others are used to monitor the temperature gradient. At the nitrogen inlet an additional plastic shield prevents direct contact between liquid nitrogen drops and the focus tube.

The nitrogen inlet and therefore the cold spot is situated at the end of the column leading to a negative temperature gradient in flow direction. This geometry slightly increases the separation of the residual gas components, because the more 
volatile gases are transported further down the temperature gradient before being retained. This pre-separation increases further as the individual components are injected to the GC column with some time delay.

The target temperature for cryofocussing is set to a value between $-150^{\circ} \mathrm{C}$ and $-130^{\circ} \mathrm{C}$. For the focus unit the regulation of the liquid nitrogen usage is realized by switching the pump on and off (throttle mode). At the end of the focusing phase a cold spot at the liquid nitrogen inlet can develop so that the temperature suddenly drops to $-185^{\circ} \mathrm{C}$ there. This has not been observed to be detrimental to the measurement precision, but causes an additional delay in the subsequent heat out and release phase and influences the peak width. After trapping, $\mathrm{CH}_{4}$ is released from the focus unit by heating to $+50{ }^{\circ} \mathrm{C}$ for about 6 minutes.

\subsection{GC separation}

A PoraPLOT Q column (Analyt; $25 \mathrm{~m}, 0.32 \mathrm{~mm}$ i.d.) was chosen because it provides excellent separation of $\mathrm{CH}_{4}$ and $\mathrm{CO}_{2}$ so that the $\mathrm{CO}_{2}$ which is combusted from the $\mathrm{CH}_{4}$ sample does not interfere with original $\mathrm{CO}_{2}$ from the sample air. Additionally, the more shock resistent PoraBOND Q version has been used, since the intensive use of switching valves should produce additional shock waves, limiting the lifetime of the PLOT-type column. No significant changes in the results were observed when a PoraBond Q column was used instead of the PoraPLOT Q column, but the process timing needs to be slightly modified. By default, the GC column is operated at a constant temperature of $+70( \pm 0.4){ }^{\circ} \mathrm{C}$. When the column needs to be cleaned, it is heated to $180^{\circ} \mathrm{C}$ for several hours.

Given the near-perfect removal of $\mathrm{CO}_{2}$ in our system before the GC column, a column with better separation of oxygen and methane may now be preferable. Oxygen turned out to be the most harmful component for hydrogen isotope analysis as it promotes the production of $\mathrm{CO}_{2}$ and $\mathrm{H}_{2} \mathrm{O}$ in the pyrolysis unit and therefore removes $\mathrm{H}_{2}$ from the sample. In fact, a large amount of tuning is necessary to safely ensure a sufficient separation of oxygen/nitrogen and methane.

\subsection{Chemical conversion}

The direct measurement of the isotopic composition of $\mathrm{CH}_{4}$ is very difficult (Jackson et al., 1999) because of strong fragmentation (nearly equal signals at mass 15 and mass 16) and because of interference of $\mathrm{O}^{+}$and $\mathrm{O}_{2}^{++}$on mass 16 and $\mathrm{OH}$ on mass 17 (here and in the following the term "mass" refers to the physically correct mass/charge ratio $\mathrm{m} / \mathrm{z}$ ). Therefore, $\mathrm{CH}_{4}$ is combusted to $\mathrm{CO}_{2}+\mathrm{H}_{2} \mathrm{O}$ for carbon isotope analysis and pyrolyzed to $\mathrm{C}+2 \mathrm{H}_{2}$ for hydrogen isotope analysis.

\subsection{1 ${ }^{13}$ C analysis}

Combustion to $\mathrm{CO}_{2}+\mathrm{H}_{2} \mathrm{O}$ takes place in an alumina tube (Friatec, Degussit AL23, $320 \mathrm{~mm}, 0.8 \mathrm{~mm}$ i.d.) that con- tains three oxidized Ni-wires (Goodfellow, purity $99.98 \%$, $0.25 \mathrm{~mm}$ diameter) as oxygen reservoir. The tube is heated in an oven to a temperature around $1130^{\circ} \mathrm{C}$ so that the use of an additional copper wires (melting point $1083{ }^{\circ} \mathrm{C}$ ) should be avoided. The oxygen content of the Ni-wires needs to be restored regularly by an oxygen injection through an additional valve (SGE0) in the MFC3 stream.

Establishing a reproducible oxidation state in the combustion oven turned out to be the most critical point for the quality of the combustion and the reproducibility of the isotope results. Remaining traces of $\mathrm{O}_{2}$ leave the $\mathrm{GC}$ column before $\mathrm{CH}_{4}$ and oxidize the Ni wire in a random manner. Although ideally this should not influence $\delta^{13} \mathrm{C}$ of $\mathrm{CO}_{2}$ formed from $\mathrm{CH}_{4}$, the conversion efficiency and $\delta$-value get much more stable when the $\mathrm{O}_{2}$ is kept out of the oven. This was realized by selecting an appropriate time window with Valve3, which ensures that only $\mathrm{CH}_{4}$ reaches the reactor, while $\mathrm{O}_{2}$ and $\mathrm{N}_{2}$ are vented. Therefore a sufficient separation of $\mathrm{O}_{2} / \mathrm{N}_{2}$ and $\mathrm{CH}_{4}$ on the GC column is essential. As a second improvement the oven is flushed with pure oxygen during each run to realize a reproducible oxidation state. The flush period (30 to 90 s) ends just a few seconds before methane reaches Valve3. The in-run-flush ensures that the oxidation state of the oven is the same for all $\mathrm{CH}_{4}$ samples and allows continuous measurements without need for manual re-oxidation.

\subsubsection{D analysis}

For D analysis, $\mathrm{CH}_{4}$ is pyrolyzed to $\mathrm{H}_{2}$ in a silica tube (Friatech, $1.5 \mathrm{~mm}$ o.d., $1.0 \mathrm{~mm}$ i.d., $320 \mathrm{~mm}$ length) that can be heated up to $1500^{\circ} \mathrm{C}$ on a hot spot. In regular tests it was established that the optimum conversion temperature is around $1330^{\circ} \mathrm{C}$. The temperature tests showed that methane destruction starts at around $600^{\circ} \mathrm{C}, \mathrm{H}_{2}$-formation gets significant around $950^{\circ} \mathrm{C}$ and increases up to a plateau of about $50 \mathrm{~K}$ at $1330^{\circ} \mathrm{C}$, which is similar to results presented in (Sofer, 1986a, b; Burgoyne and Hayes, 1998) that focus more on studies of higher hydrocarbons. Above $1350{ }^{\circ} \mathrm{C}$ the $\mathrm{H}_{2}$ yield in our system decreases again, which is likely due to the tube porosity increasing with temperature.

During $\mathrm{CH}_{4}$ pyrolysis, $\mathrm{H}_{2}$ is formed and elemental $\mathrm{C}$ is deposited on the reactor surface. This carbon layer turns out to be essential for an efficient $\mathrm{H}_{2}$-production from $\mathrm{CH}_{4}$ pyrolysis. Typically, after a longer break, the first measurement does not produce any or at least a significantly smaller $\mathrm{H}_{2}-$ signal, although $\mathrm{CH}_{4}$ is destroyed. The $\mathrm{H}_{2}$-production stabilizes within 6 measurements.

On the other hand, extensive carbon conditioning has a negative effect on the $\mathrm{H}_{2}$-production. Initially a $1 \% \mathrm{CH}_{4}$ in $\mathrm{He}$ mixture was injected repeatedly into the pyrolysis oven for several seconds, but if this is done, after some time $\mathrm{H}_{2}$ formation suddenly breaks down and peak areas decrease rapidly. This decrease in area occurs earlier at lower oven temperature. In this situation an $\mathrm{O}_{2}$ flush produces a lot of $\mathrm{CO}$ and $\mathrm{CO}_{2}$ in the furnace, but afterwards the $\mathrm{H}_{2}$-production 

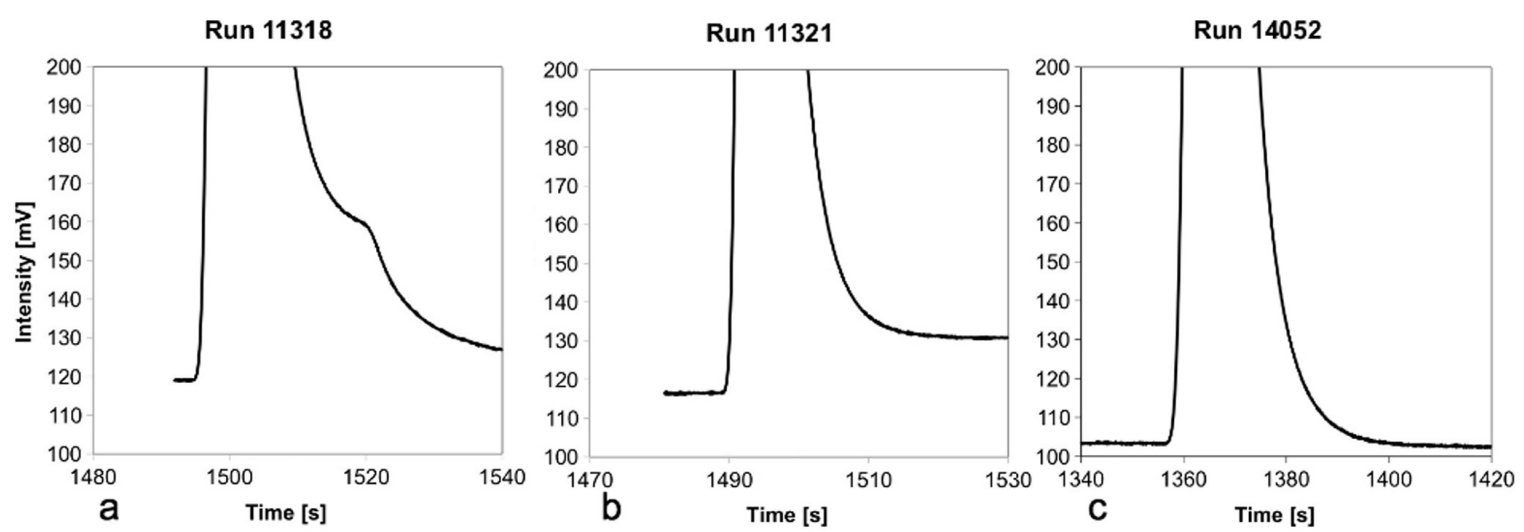

Fig. 4. (a) Before the liquid nitrogen in front of the pyrolysis furnace was introduced, the peak tail showed a "shoulder" (a) or was significant above the background level (b). The front trap improves the peak shape of the sample, especially at the tail (c). Trapped components are vented to the open spilt with a high flow rate after the sample detection is complete.

starts to restabilize at the former level. In this context the use of higher hydrocarbons for the carbon conditioning is not favorable and in the meantime has been reported to be less efficient (see (Bilke and Mosandl, 2002) for the effect of hexane). The most reliable and reproducible way to prepare a carbon layer is simply to run several measurements in an uninterrupted sequence.

As $\mathrm{O}_{2}$ affects the carbon layer in the reactor, it is important that oxygen in any form does not enter the furnace, especially during methane pyrolysis. Therefore, an additional liquid nitrogen trap (fused silica capillary inside a $1 / 16^{\prime \prime}$ stainless steel tube) is placed right in front of the pyrolysis oven to retain remaining traces of condensable species like $\mathrm{H}_{2} \mathrm{O}$ and $\mathrm{CO}_{2}$ on the cold capillary surface. $\mathrm{CH}_{4}, \mathrm{O}_{2}$ and $\mathrm{N}_{2}$ will not be retained. The trap is lowered into a $1 \mathrm{~N}_{2}$ bath before the sample $\mathrm{CH}_{4}$ peak passes and removed after the peak has been recorded in the mass spectrometer. The front trap has a direct influence on the $\mathrm{H}_{2}$ peak shape, especially its tailing. Before the trap was introduced, the peak tail showed a "shoulder" (Fig. 4a) or was significant above the background level (Fig. 4b). With an active trap, the peak area slightly increases, shoulders are removed and the peak end is now slightly below the background level (Fig. 4c).

Tests indicate that the total hydrogen yield is $(97 \pm 3) \%$. This yield is estimated from the observed hydrogen peak area in comparison to what is expected for complete conversion. Consequently, the results must be thoroughly checked for possible fractionation. Losses can potentially occur at many places, e.g. cutting the peak by valve switching, incomplete trapping and/or release, incomplete pyrolysis or subsequent loss of $\mathrm{H}_{2}$, and cutting of the peak tail by the evaluation software. Such losses do not necessarily cause problems because the primary target is to measure reproducible values that represent the isotope ratio of the individual samples. The final isotope results are determined relative to a calibrated reference gas that has to undergo the same procedure (Werner and Brand, 2001).

\subsection{Open split interface and mass spectrometry}

The sample is introduced to the mass spectrometer via an open split interface using a ThermoFinnigan GasBench II unit. The flow rate of the sample capillary is controlled by MFC1 and it can be lowered ( $\sim 0.4 \mathrm{~mL} / \mathrm{min})$ when the sample enters the IRMS to decrease the split ratio, whereas it is high $(3.2 \mathrm{~mL} / \mathrm{min})$ when potential contaminations may enter to increase the split ratio. The mass spectrometer capillary restricts the flow rate to the MS to $\sim 0.3 \mathrm{~mL} / \mathrm{min}$ and the vacuum in the ion chamber of the mass spectrometer is $\sim 3 \times 10^{-6} \mathrm{mbar}$. To keep the system as dry as possible, the original NAFION tube, which removes water from the passing gas stream, was replaced by a longer version with a higher $(\sim 40 \mathrm{~mL} / \mathrm{min}$ ) helium counter flow (Leckrone and Hayes, 1997). The GasBench interface also allows injecting square peaks of a mass spectrometer running gas through a second split system (reference split). The two split capillaries are connected at a T-piece before the MS. Thus, GasBench He-pressure and sample flow rate slightly influence each other. As a result the background signal changes with the He-pressure and the reference peak size changes with the sample flow rate.

\subsection{Control unit}

The control unit (V25) developed at the Max Planck Institute for Chemistry, Mainz, Germany has a firmware that provides an integrated PASCAL/JAVA-like compiler (limited command set, but offering basic object oriented programming, multi-threading, event handling) that allows to realize instrument controls quite comfortably. It is based on an embedded 286-compatible board, which is extended to use a wide range of interface cards, e.g. thermocouple readout (ADC), mass flow controller interface, switchable $24 \mathrm{~V}$ output. A DOS program is available to remote control the V25 via a RS232 
interface (COM port). Parameter changes can be done even when a measurement is running, so the operator can intervene at any time.

The control software is responsible for temperature readout and control for HSD column, focus and GC column, mass flow controller communication, timed valve switching (pneumatic and electrical, RS232), pressure readout, data logging, liquid nitrogen pumps control, oxygen and methane flush and sequence handling including process interpreter and sample selection. The ThermoFinnigan ISODAT software is used to handle the GasBench elements, i.e., the open split, the reference split and the liquid nitrogen front trap (hydrogen analysis). The two programs are synchronized through their time schedule, i.e., the runtime of an ISODAT run (method) is adjusted to fit a V25 run (process).

\subsubsection{Details of the temperature control}

Temperatures are controlled via a PID-controller module in the V25 firmware. This module is used to keep the GC column at constant temperature (default: $70 \pm 0.4{ }^{\circ} \mathrm{C}$ ). For the two cooling units (HSD, focus), four "states" were defined for each unit, containing an optimized set of control parameters for heating and for cooling. These states reflect the actual operating mode, i.e., idle mode, trapping mode, release mode and cleaning mode. Additionally, each state is split in the two phases "transit" (trying to reach the target temperature) and "hold" (keeping the target temperature).

The cooling pump for the HSD unit is controlled by providing a reference voltage between 3.5 and $10 \mathrm{~V}$ to the variable pump, which corresponds to flow rates between 0 and $1.3 \mathrm{~m}^{3} / \mathrm{h}$. The cooling control for the focus unit is realized by interrupted pumping (throttling). In a predefined time interval (cycle time) the pump is turned on for a certain percentage of the cycle time and stays off for the rest. For example, for a cycle time of ten seconds and an active time of $20 \%$, in every ten second interval the pump is on for two seconds and off for eight seconds.

Counter heating is used to keep a unit at a constant temperature. The strength of the counter heating is used to regulate the cooling pumps. If the compensating counter heating lies above a threshold value then the cooling percentage is decreased (and vice versa). After some delay the decreased nitrogen usage will reduce the necessary counter heating, so in the end heating current and cooling strength are minimized, leading to the most stable temperature, the lowest temperature gradient and minimized nitrogen usage. The start conditions of a measurement process change from run to run because the whole cooling units get colder. The most extreme example is the first run after a break. The HSD unit starts at room temperature, while for the following runs its starting temperature stays below zero $\left(\sim-30^{\circ} \mathrm{C}\right.$ to $\left.-70^{\circ} \mathrm{C}\right)$, because the brass shields are not heated up to room temperature at the end of the actual measurement. Thus the cooling speeds up, which saves liquid nitrogen, and cooling gets more effi- cient. As the units get colder in total, the heating needs to be slightly increased (heating becomes less efficient, due to the colder surrounding), thus the relative strength of heating and cooling change from run to run.

\subsection{Isotope measurement and data reduction}

Isotope measurements are carried out using a ThermoFinnigan MAT Delta ${ }^{\text {plus }}$ XL isotope ratio mass spectrometer. During a single run the isotope composition of the sample peak is compared to a MS running gas that is admitted from the reference open split unit. Following the "identical treatment" principle (Werner and Brand, 2001), this value is then compared to a measurement of air from a reference air cylinder (SiL, see below) that follows or precedes the sample measurement to establish the isotopic difference between sample and reference. In practice, each sample is usually measured at least twice according to the following scheme: SiLsample-sample-SiL, or, when the system is running very stable, SiL-sample1-sample1-sample2-sample2-SiL. When such a "package" of measurements is repeated, usually the difference between the mean results from the two packages is smaller than the differences between the two measurements within a package. The sample concentration is derived from the peak area ratio (relArea)

$c_{\text {Sample }}=c_{\mathrm{SiL}} \cdot$ relArea $=c_{\mathrm{SiL}} \cdot \frac{\text { peak area }(\text { sample })}{\text { peak area }(\mathrm{SiL})}$

In the following chapters the $\Delta$-difference between two samples $\mathrm{A}$ and $\mathrm{B} \Delta(\mathrm{A}-\mathrm{B})=\delta(\mathrm{A})-\delta(\mathrm{B})$ is used to quantify isotope differences. $\Delta(\mathrm{A}-\mathrm{B})$ differs from the relative measurement $\delta_{\mathrm{B}}(\mathrm{A})$ by a scaling factor and it defines a difference of two $\delta$-values on their common scale. All $\delta \mathrm{D}$ values and $\triangle \mathrm{D}$ differences are given on the VSMOW-scale (for ${ }^{13} \mathrm{C}$ on the VPDB-scale). VSMOW (Vienna Standard Mean Ocean Water) and VPDB (Vienna Pee Dee Belemnite) are the international standards for hydrogen and oxygen isotopic composition. The $\delta$-value of a sample is calculated from the $\Delta$ difference and the known $\delta$-value of the reference air, e.g.

$$
\begin{aligned}
& \delta \mathrm{D}(\text { sample })=\delta \mathrm{D}(\mathrm{SiL})_{\text {real }}+\Delta \mathrm{D}(\text { sample }, \mathrm{SiL})= \\
& \delta \mathrm{D}(\mathrm{SiL})_{\text {real }}+\delta \mathrm{D}(\text { sample })_{\text {meas. }}-\delta \mathrm{D}(\mathrm{SiL})_{\text {meas. }}
\end{aligned}
$$

The actual reference air standard is a 301 aluminum cylinder (Scott Marrin Inc.) that was filled to 200 bar with atmospheric air on 5 March 2003 at the Schauinsland station in the Black Forest, Germany (referred to as SiL). This air cylinder has been calibrated versus international standard materials (see chapter 4). The ISODAT NT software applies necessary ion corrections, like the $\mathrm{H}_{3}$-factor correction for $\mathrm{H}_{2}$ or the ${ }^{17} \mathrm{O}$-correction for $\mathrm{CO}_{2}$, determines the total peak area, and the atomic isotope ratio for peaks detected. Carbon isotope measurements are usually evaluated with the ISODAT NT software, for hydrogen analysis a custom-made software is used (see below). 


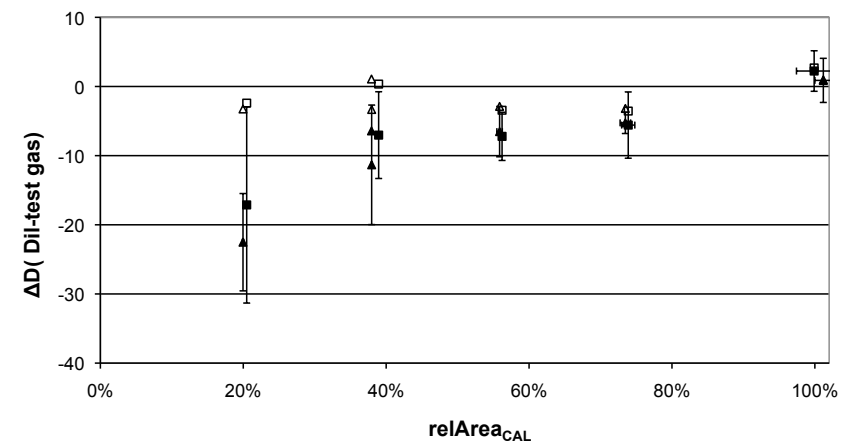

Fig. 5. The non-linearity for the two calibration gases CAL-2 (triangle, $\delta \mathrm{D}=-19 \%$ ) and CAL-3 (square, $\delta \mathrm{D}=-164.9 \%$ ) shows no significant dependence on their $\delta$-value (closed symbols with error bars evaluated with ISODAT NT5), which allows SPI to correct both (open symbols) using only a single parameter to lower the derived median background on mass 3 . The error bars represent the standard deviation of repeated measurements.

\section{Hydrogen peak integration}

During the development of the analytical procedure and the extensive testing period, it became obvious that in particular for deuterium analysis, the detection of the peak background is a very sensitive parameter for the quality (reproducibility, linearity and robustness) of the final results. The measurements were first evaluated using different peak integration routines available in the original ISODAT software. Evaluation with a "TimeBased BGD" led to highly reproducible results (for constant peak area), but showed a clear non-linearity, i.e. the $\delta$-values depend on the peak area and therefore for the sample size analysed (Fig. 5). On the other hand, evaluation with the standard option "Individual BGD" showed significantly higher scatter (poor reproducibility) for repeated measurements, but non-linearity effects were strongly attenuated or even fully absent. The issue with the "Individual $B G D$ " routine is that it is mainly defined by the minimum recorded value in the specified history before each peak, after some filtering of the raw data. This makes the results sensitive to individual negative outliers and causes a relatively large scatter. Options that assign a statistically more robust background value (e.g. the "TimeBased $B G D$ ", but also other options) reduce the scatter. However, the specific choice of the background level can cause systematic deviations in the peak area calculations, which usually leads to a non-linearity in the $\delta$ value. These considerations led to the development of a new peak integration software (Stream Peak Integrator, SPI), which is based on two ideas:

1. The background is first determined as the median value of the specified background history before a peak, which is least affected by individual outliers. Compared to the default setting in ISODAT, the history size is greatly extended (between $50 \mathrm{~s}$ and $200 \mathrm{~s}$ ) to statistically strengthen the determined background level and make the values more robust for run-to-run comparisons. Of course, the extended history is only useful when the background is stable (which was achieved by improvements in hardware and control software development). Although a long stable history is found before the sample peak, this is not necessarily the case for the reference peaks. As a first improvement, the SPI routines allow defining the size of the history for each peak number in a chromatogram individually. A second improvement allows a more variable choice of the history position relative to the peak, i.e. it does not need to extend up to the peak start. In some cases the background right before the peak shows increased fluctuations. For SPI evaluations, typically $8-40$ data points ( 1 to $5 \mathrm{~s}$ ) lie between peak and its background history, and they are kept constant for the entire measurement series.

2. The detected background level is then adjusted by a constant value for all measurements in a certain measurement period, which causes a non-linear correction of the $\delta$-values. In an optimization routine the size of this adjustment parameter is defined such that the linearity runs in this period show the smallest non-linearity. Choosing exactly the median value of the background leads to non-linear $\delta$ values, like in ISODAT NT.

The crucial correction that is performed in SPI is to lower the detected median background by a defined number, which is constant for the whole measurement series. The criterion for the choice of this parameter is to minimize the nonlinearity effects. Conceptually, also the ISODAT NT "Individual BGD" routine selects a background level between mean and minimum with the help of a (not published) filter function. But instead of a fixed filter rule, SPI takes into account the characteristics of the measurement series (tailing, peak shape, non-constant backgrounds, drifts in the history and/or really fractionated sample methane, incomplete pyrolysis) by adjusting this offset parameter to minimize nonlinearity. The exact size of the offset is derived by repeatedly evaluating linearity tests with slightly different background levels. The optimal offset is the one for which the results distribute symmetrically around $\Delta \mathrm{D}=0$ for the entire measurement series with variable peak areas. The range of peak areas is chosen to include the lowest sample concentration available in the corresponding atmospheric sample set to be analyzed. In practice, the offset is only optimized for the mass 3 signal, so that the concentration determination, which mainly relies on the mass 2 signal, is unaffected. For mass 3 , the optimal offset is always between 0 and $-1 \sigma$ of the distribution in the background history (typical values are around $-0.45 \mathrm{mV}$ ). The above criterion allows defining the offset precisely (within $0.05 \mathrm{mV}$ ). When the offset has been optimized, the final $\delta$-values, even for the lowest concentration samples, are not very sensitive to the precise value, i.e. the measurement error is bigger than the shifts due to shifts in the offset of $0.05 \mathrm{mV}$. 


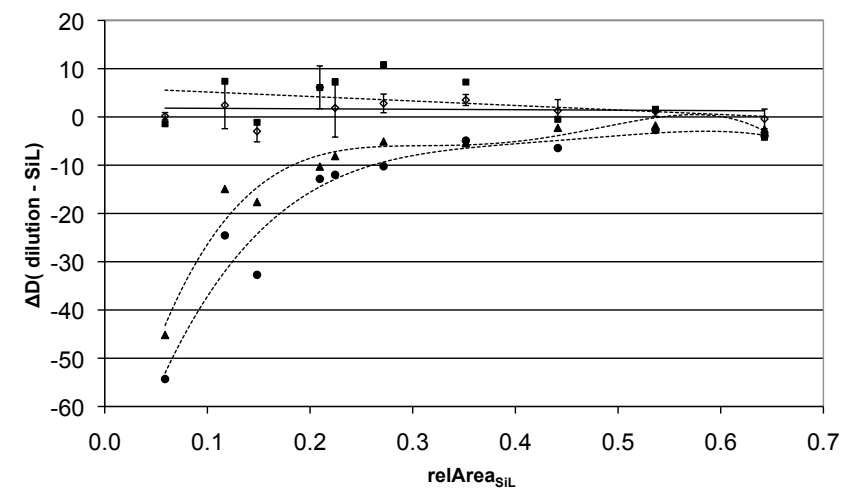

Fig. 6. Resulting non-linearity for different background detection algorithms. The trend lines (linear for SPI and Individual BGD, polynomial order 4 for TimeBased BGD and Median BGD) illustrate the basic tendencies. Error bars are only included for SPI. For this special sample set SPI determined a background offset of $-0.35 \mathrm{mV}$ on mass 3 . For comparison the typical standard deviation of the background in the history was $\sim 0.4 \mathrm{mV}$. $\diamond$ SPI (straight line), ם "Individual BDG", « "Median BGD", • "TimeBased BGD (440-520s).

Compared to conventional non-linearity corrections, which are often carried out by determining a fit to the nonlinearity curve ( $\delta$ value versus some measure of sample size), in the new method the real sample size does not need to be known and it is not necessary to derive an empirical fit function. Thus the non-linearity correction is done implicitly and uncertainties in the concentration determination do not propagate to $\Delta \mathrm{D}$.

\subsection{SPI vs. ISODAT NT: comparison of results}

Results obtained with the new SPI integration have been compared to results derived with ISODAT for about 100 samples from stratospheric balloon flights, covering concentrations from $200 \mathrm{ppb}$ to $1800 \mathrm{ppb}$ (peak areas vary between $1 \mathrm{Vs}$ and $12 \mathrm{Vs}$ ).

\subsection{1 $\mathrm{H}_{3}^{+}$-Factor}

The $\mathrm{H}_{3}^{+}$-factor is determined according to the ISODAT manual, i.e. 10 to 26 square-shaped peaks of reference $\mathrm{H}_{2}$ are injected through the reference split of the GasBench. The peak amplitudes and peak areas are subsequently increased by increasing the reference gas pressure, while peak widths stay essentially equal. The $\mathrm{H}_{3}^{+}$-factor is derived from a linear regression of the molecular ratio against mass 2 area. Consequently, an area-based $\mathrm{H}_{3}^{+}$-correction is performed.

For the main $\delta \mathrm{D}$ measurement phase from January 2002 to November 2004 the $\mathrm{H}_{3}^{+}$-factor ISODAT is $5 \pm 1.5 \mathrm{ppm} / \mathrm{nA}$. Repeated $\mathrm{H}_{3}^{+}$-factor determinations usually agree within 0.08 $\mathrm{ppm} / \mathrm{nA}$. For the dataset presented in Fig. 7, a shift of the $\mathrm{H}_{3}^{+}$factor of $+0.5 \mathrm{ppm} / \mathrm{nA}$ leads to a shift of $+0.05 \%$ in $\delta \mathrm{D}_{\mathrm{SiL}}$ calibration.

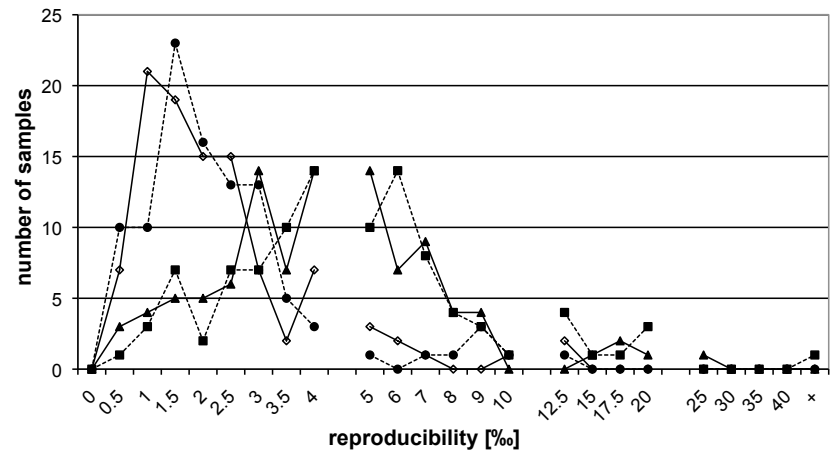

Fig. 7. Reproducibility distribution. The line breaks indicate a change of the $\mathrm{x}$-axis scale. $\diamond \mathrm{SPI}, \mathbf{\square}$ "Individual BDG", $\boldsymbol{\Delta}$ "Median BGD”, • "TimeBased BGD (440-520 s).

\subsubsection{Linearity}

First, a linearity test that covers the respective range of peak areas $(0.55$ to $10.8 \mathrm{Vs})$ was carried out. The smallest peak size corresponds to a methane concentration of $\sim 130 \mathrm{ppb}$ and is included to extrapolate the fractionation correction beyond the lowest sample concentration. The relevant data points used for the correction are relArea $>0.105(>200 \mathrm{ppb})$.

In Fig. 6 the strong non-linearity resulting from the ISODAT evaluation routines "MedianMean BGD" and "TimeBased BGD" is obvious. The option "Individual $B G D$ " and SPI show good linearity. For SPI with optimal background offset the overall fractionation is lowest (worst case: $+\Delta \mathrm{D}<=6 \%$ ) , i.e. deviations are smaller than for "Individual BGD" (8-12\%o for relArea <0.375). It should be noted that evaluation of a large number of linearity tests with the standard "Individual $B G D$ " routine showed a positive $\Delta \mathrm{D}$ elevation around $\sim 30 \%$ of the maximum peak area, where it usually exceeds the uncertainty in the $\mathrm{H}_{3}$ factor. This is also true for SPI, but the background offset correction reduces this deviation.

\subsubsection{Reproducibility}

The distribution of the reproducibility for different evaluation routines is shown in Fig. 7. The reproducibility is defined as standard deviation of repeated measurements of "sample packages" as described in Sect. 2.9. A large set of $\sim 100$ samples was measured and then the peaks evaluated with different ISODAT integration routines, and the new SPI integration. Figure 7 shows the reproducibility distribution of the different integration routines and Table 1 lists the main characteristics of this distribution.

For the "Individual $B G D$ " the reproducibility distribution peaks between 4 and $6 \%$. The worst reproducibility for an individual sample is $>40 \%$ o. The "MedianMean BGD" routine is slightly better, the peak of the distribution is between $3-5 \%$ and the largest deviation $\sim 25 \%$. However, it produces a severe non-linearity. When the peaks are evaluated with the 
Table 1. Reproducibilities obtained for several evaluation methods. The SPI-type evaluation results in the lowest deviation from the linearity of all evaluation methods. Compared to the ISODAT evaluations SPI improves the overall and the individual reproducibility.

\begin{tabular}{lcccc}
\hline Evaluation type & Individual BGD & SPI & TimeBased BGD & Median BGD \\
\hline $\begin{array}{l}\text { Maximum of reproducibility } \\
\text { distribution at } \sim \% \% \text { ] }\end{array}$ & 5 & 1.25 & 1.5 & 4 \\
Worst case reproducibility [\%] & 44 & 11 & & \\
95\% of samples below [\%o] & 15 & 5.5 & 8 & 25 \\
Non-linearity* [\%] & -4 to +10 & -3 to +6 & -54 to -3 & -45 to -2 \\
$\Delta \mathrm{D}_{\max }$ (diluted, undiluted) & & & & \\
\hline
\end{tabular}

* Compare Fig. 5 .

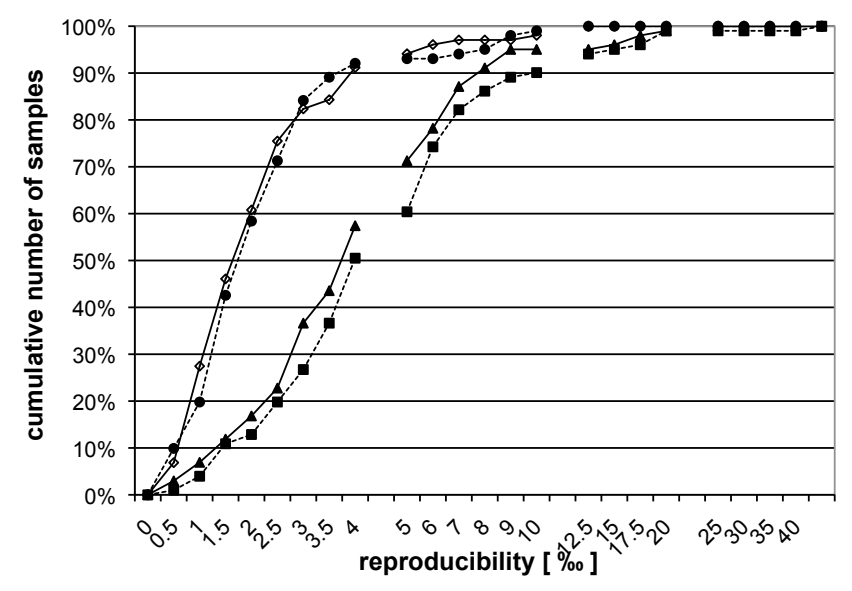

Fig. 8. Cumulative number of samples (in percent) with an reproducibility better than a given level. The line breaks indicate a change of the x-axis scale. $\diamond$ SPI, $\mathbf{\square}$ "Individual BDG", $\boldsymbol{\Delta}$ "Median BGD", • "TimeBased BGD (440-520 s).

option "TimeBased BGD" with a long period for background evaluation, the reproducibility improves strongly (peak at $1.5 \%$, worst case $11 \%$ ), but again this method produces a severe non-linearity. SPI provides the best reproducibility distribution, a maximum between 1.0 and $1.5 \%$, a worst case of deviation of $11 \%$ and no significant non-linearity. Less detailed, but more descriptive is the view of the cumulative number of samples (given in percent) that have been measured with reproducibility better than a given level (Fig. 8). Around $66 \%$ of SPI results were found below $2.3 \%$, while for the "Individual BGD" this is reached at 5.5\%, where SPI already reaches the $95 \%$-level.

To summarize, SPI combines the good reproducibility of the "TimeBased BGD" with the good linearity of the "Individual BGD" options of the ISODAT software, and it even slightly improves both and operates much faster. The typical reproducibility of the system is $2.3 \%$ for $\delta \mathrm{D}$ measurements, as determined from a large suite of real air samples.

\section{Data reduction and calibration}

\section{1 $\mathrm{CH}_{4}$ mixing ratio}

Although a CF-IRMS system is primarily designed for high precision isotope measurements, the mixing ratio can also be determined with reasonable precision from the peak areas. For this we use the measurement of the sum of peak areas for all observed isotopes. Typically two independent results from the analyses of $\delta \mathrm{D}$ and $\delta^{13} \mathrm{C}$ are available, which show a good linear correlation, but there is a positive offset between the concentration derived from the $\delta \mathrm{D}$ measurement compared to the concentration derived from the $\delta^{13} \mathrm{C}$ measurement. It is reasonable to assume that the reason for the discrepancy is in the hydrogen measurement, since the pyrolysis could not be proven to be complete. Therefore the "hydrogen"-derived concentrations are linearly corrected to match the "carbon" scale before calculating the average of both. The difference of the rescaled "hydrogen"-derived mixing ratios to the final mean mixing ratios is given in Table 2 for two stratospheric data sets. The maximum difference $M$ is $36 \mathrm{ppb}$, and the average difference within a set of samples is 6-7 ppb with a standard deviation of $6 \mathrm{ppb}$. This shows that the isotope system produces high precision mixing ratio data.

The methane mixing ratio scale is linked to international standards using a calibration of the SiL reference air cylinder by the Institut für Umweltphysik, University of Heidelberg, Germany (Levin et al., 1999), which yielded a value of $1899.5 \pm 2.6 \mathrm{ppb}$ on the NOAA04 scale (Dlugokencky et al., 2005). It should be noted that this is a 1-point calibration, but comparison for measurements on a large set of stratospheric air samples shows an excellent agreement over the range 200-1800 ppm (Fig. 9). Comparison for several individual sample sets from stratospheric balloon flights show that $66 \%$ of the GC-IRMS measurements agree within the IUP data within $18 \mathrm{ppb}$, and we assign this value as $1-\sigma$ standard deviation of $\mathrm{CH}_{4}$ results. 


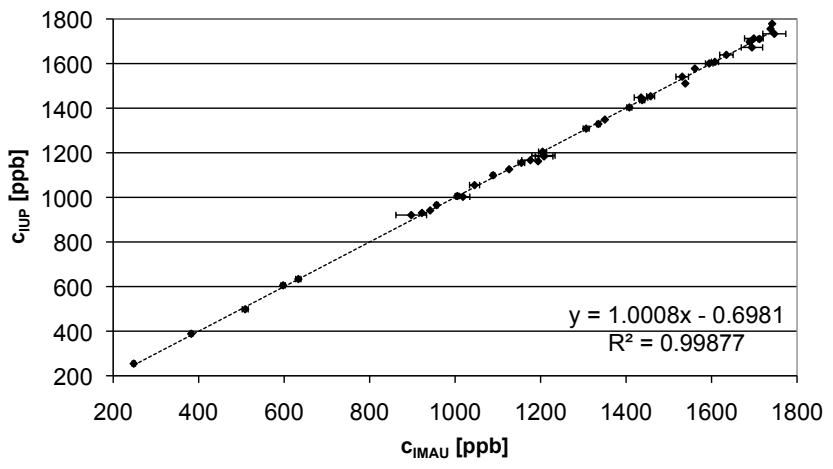

Fig. 9. Comparison of the concentrations for balloon flights B37B39 measured with the GC-IRMS technique (x-axis) to the IUP results (y-axis). Usually an excellent linear correlation with a small offset is found.

\section{2 $\delta \mathrm{D}$ calibration}

The $\delta \mathrm{D}$ scale is established using three high concentration $(\sim 9000 \mathrm{ppm})$ calibration gases provided by the MPI for Chemistry, Mainz, Germany, that were developed as calibration gases for a tunable diode laser system (Bergamaschi et al., 1994). The nominal $\delta$ values for these gases are: $\delta \mathrm{D}_{\mathrm{CAL} 1}=25.9 \%, \delta \mathrm{D}_{\mathrm{CAL} 2}=-19 \%$, $\delta \mathrm{D}_{\mathrm{CAL1}}=-164.9 \%$ o. These calibration gases were mixed into $\mathrm{CH}_{4}$-free synthetic air to near-atmospheric mixing ratios $(\sim 2 \mathrm{ppm})$ and CAL1 and CAL2 were additionally diluted in He to $\sim 2 \mathrm{ppm}$. The differently diluted gases are called in the following "air-calibration gases" and "He-calibration gases".

\subsubsection{Influence of the bath gas}

Table 3 shows the isotope differences between the SIL reference gas and the calibration gases CAL1 and CAL2 diluted either in air or He. Whereas it is hard to reliably quantify the difference with the original ISODAT NT software, the difference can be precisely quantified with the SPI software. The He-diluted samples are constantly measured 7\%o (of VSMOW) heavier. As $\mathrm{CH}_{4}$ - air-mixtures are closer to an air sample than $\mathrm{CH}_{4}-\mathrm{He}$ mixtures, the air mixtures are used for routine calibration.

\subsubsection{Verification of the calibration gases, recalibration of CAL-1}

The $\Delta$-difference $\Delta($ CAL2-CAL3 $)=145.9 \%$ assigned to the gases by the MPI for Chemistry has been verified numerous times $(146.7 \pm 1.8 \%$ o). However, Table 4 shows that $\Delta$ (CAL1-CAL2) typically is measured to be $40 \%$, whereas it should be nominally $44.4 \%$. Although the difference is within the statistical error of some individual measurements, this was verified several times and with higher accuracy in later measurements. A possible fractionation in the preparation process (dilution) is highly unlikely, because the two He-diluted gases produce the same difference as the two air-
Table 2. Differences between the individual rescaled hydrogen mixing ratio measurements and the combined "final" results. $n$ : number of samples in respective sample set; $M$ : Maximum difference; $\mu$ : average difference; $\sigma:$ standard deviation of difference.

\begin{tabular}{lllll}
\hline Sample set & $n$ & $M$ & $\mu$ & $\sigma$ \\
& {$[1]$} & {$[\mathrm{ppb}]$} & {$[\mathrm{ppb}]$} & {$[\mathrm{ppb}]$} \\
\hline Balloon samples 87-99 & 87 & 36 & 6 & 6 \\
EUPLEX samples & 82 & 23 & 7 & 6 \\
\hline
\end{tabular}

diluted gases. Therefore, based on our measurements over several years, we revise the value for CAL1 reported by MPI$\mathrm{C}$ to $21.1 \%$ o to be consistent with CAL2 and CAL3 Table 5 summarizes all results obtained for the calibration gases over the last years.

\subsubsection{Assignment of $\delta \mathrm{D}$ value to laboratory reference gas}

To finally derive $\delta \mathrm{D}(\mathrm{SiL})$ the assigned $\delta$-values of the CAL gases are plotted versus their measured differences to SiL, i.e. $\Delta(\mathrm{CAL}-\mathrm{x}-\mathrm{SiL})$. The $\mathrm{y}$-intercept of a linear fit then returns $\delta \mathrm{D}(\mathrm{SiL})$. This elaborate calibration strategy has been applied in 9 extended measurement periods over the last years when large stratospheric and tropospheric sample sets were measured. The average value for the SIL cylinder from this calibration effort is $\delta D_{\text {VSMOW }}(\mathrm{SiL})=-92.29 \pm 0.66 \%$, where the error reflects the $1 . \sigma$ standard deviation of the 9 calibrations. It should be noted that the final result is not very sensitive to the recalibration of CAL1. Actually, the difference is within the standard deviation of the final value reported above.

\section{3 $\quad \delta^{13} \mathrm{C}$ calibration}

All stated $\delta^{13} \mathrm{C}$ values and $\delta$-differences are given on the $\mathrm{V}$ PDB scale. For the ${ }^{17} \mathrm{O}$-correction the Santrock algorithm (Santrock et al., 1985) integrated in the ISODAT NT software is used.

The assignment of $\delta^{13} \mathrm{C}(\mathrm{SiL})$ is similar to the one for $\delta \mathrm{D}(\mathrm{SiL})$ (see Sect. 4.2). However, instead of dedicated calibration gases a set of 13 firn air samples from Dome Concordia (DC in the following), Antarctica $\left(75^{\circ} 06^{\prime} \mathrm{S}, 123^{\circ} 23^{\prime} \mathrm{E}\right)$, provided by the MPI for Chemistry in Mainz, Germany, are used to establish the scale. These samples were analyzed by the MPI Mainz and the Laboratoire de Géologie et Géophysique de l'Environnement (LGGE), Grenoble, France (Bräunlich et al., 2001) and cover a $\delta^{13} \mathrm{C}$ range of $3 \%$. The original results from both institutes are nearly equal apart from the deepest samples, which in fact are assumed to be physically different, since the two labs used different samples from the same depth. As we analyzed the sample set from MPI, their results are used. Additionally, there is a 
Table 3. Comparison of isotope reference gases diluted in He and air, respectively, with the two available evaluation methods. SPI significantly proves that He-diluted gases are measured heavier than air-diluted gases.

\begin{tabular}{|c|c|c|c|c|c|c|}
\hline \multirow{3}{*}{$\begin{array}{l}\text { He-Air } \\
\text { comparison }\end{array}$} & \multicolumn{3}{|c|}{ ISODAT NT (Individual BGD) } & \multicolumn{3}{|c|}{ SPI } \\
\hline & $\Delta\left(\mathrm{CAL}_{\mathrm{He}}-\mathrm{SiL}\right)$ & $\Delta\left(\mathrm{CAL}_{\mathrm{Air}}-\mathrm{SiL}\right)$ & $\Delta($ Air-He $)$ & $\Delta\left(\mathrm{CAL}_{\mathrm{He}}-\mathrm{SiL}\right)$ & $\Delta\left(\mathrm{CAL}_{\mathrm{Air}}-\mathrm{SiL}\right)$ & $\Delta(\mathrm{Air}-\mathrm{He})$ \\
\hline & \%orvSMOW & $\%$ rVSMOW & $\% o r$ VSMOW & \%orVSMOW & \%orVSMOW & $\%$ r r VSMOW \\
\hline CAL1 & $124.7 \pm 7.4$ & $112.5 \pm 8.4$ & $-12.2 \pm 11.2$ & $120.2 \pm 1.1$ & $112.7 \pm 1.8$ & $-7.5 \pm 2.1$ \\
\hline CAL1 & $119.8 \pm 4.5$ & $108.8 \pm 5.9$ & $-11.0 \pm 4.5$ & $120.3 \pm$ & $113.3 \pm 3.6$ & $-7.0 \pm 3.6$ \\
\hline CAL1 & $123.0 \pm 2.8$ & $117.5 \pm 4.8$ & $-5.5 \pm 5.6$ & $121.4 \pm 4.3$ & $113.8 \pm 0.8$ & $-7.6 \pm 4.4$ \\
\hline CAL2 & $82.1 \pm 4.6$ & $81.9 \pm 1.2$ & $-0.2 \pm 4.8$ & $80.9 \pm 1.0$ & $74.3 \pm 0.7$ & $-6.6 \pm 1.2$ \\
\hline CAL1 & $121.7 \pm 9.8$ & $118.1 \pm 3.9$ & $-3.6 \pm 10.5$ & $122.1 \pm 1.3$ & $114.5 \pm 0.2$ & $-7.6 \pm 1.3$ \\
\hline mean & & & $-6.5 \pm 5.1$ & & & $-7.3 \pm 0.4$ \\
\hline
\end{tabular}

Table 4. Measured $\delta$-difference $\Delta(\mathrm{CAL} 1-\mathrm{CAL} 2)$. The difference is measured $4 \%$ o smaller than the nominal value of $44.4 \%$. This would be hardly detectable with the ISODAT evaluation, but is clearly significant with the SPI evaluation. The differences stated in the first two rows are calculated from two separate sequences comparing a single gas to SiL, while the third row is determined from a direct comparison of CAL1 and CAL2 within a single sequence.

\begin{tabular}{lcc}
\hline & $\begin{array}{c}\text { ISODAT NT (Individual BGD) } \\
\Delta(\text { CAL1-CAL2) }\end{array}$ & $\begin{array}{c}\text { SPI } \\
\text { (CAL1-CAL2) }\end{array}$ \\
\hline He-diluted & $40.25 \pm 11.18$ & $40.85 \pm 4.60$ \\
Air-diluted & $35.90 \pm 6.30$ & $39.85 \pm 1.08$ \\
Air (directly) & $40.50 \pm 5.03$ & $40.70 \pm 4.06$ \\
mean & $38.9 \pm 2.6$ & $40.5 \pm 0.5$ \\
\hline
\end{tabular}

minor difference $(0.20 \%$ ) between the institutes for sample DC5. As our measurements reproduce the LGGE result and the MPI result is regularly found to be a minor outlier (in the measured $\Delta$-differences to SiL) the LGGE value is assigned to this sample.

The two samples DC3 and DC10 with a $\delta$-difference $\Delta($ DC3-DC10 $)=1.00 \%$ (MPI value, LGGE: $1.09 \%$ ) are slightly heavier (DC3) and slightly lighter (DC10) than SiL. They have been analyzed for every measurement series. It is intriguing that the difference between these samples is on average measured as $\triangle(\mathrm{DC} 3-\mathrm{DC} 10)=0.93 \%$, thus only $93 \%$ of the value from (Bräunlich et al., 2001), although the error bars are generally consistent with a slope of 1 . Apart from this systematic uncertainty, the value of $\delta^{13} \mathrm{C}(\mathrm{SiL})$ lies within the range covered by the DC samples, so that $\delta^{13} \mathrm{C}(\mathrm{SiL})$ can be calibrated very reproducibly using these samples. To assign the final $\delta^{13} \mathrm{C}$ value, the $\Delta(\mathrm{DC}-\mathrm{SiL})$ values are plotted versus $\delta^{13} \mathrm{C}(\mathrm{DC})$ and the $\mathrm{y}$-axis intercept returns $\delta^{13} \mathrm{C}(\mathrm{SiL})$. The average of all calibration procedures carried out this way yields $\delta^{13} \mathrm{C}_{\mathrm{VPDB}}(\mathrm{SIL})=-48.00 \pm 0.02 \%$. The typical reproducibility of the system for $\delta^{13} \mathrm{C}$, determined on sample pairs as described above for $\delta \mathrm{D}$, is $\pm 0.07 \%$. Although all results measured on the isotope system described here are internally
Table 5. Mean measured $\Delta$-differences and derived concentrations for the three air-diluted $\delta$ D calibration gases CAL1 to CAL3 and the two He-diluted gases evaluated with the SPI-Software. Errors denote the $1 . \sigma$ standard deviation.

\begin{tabular}{lrcc}
\hline & nominal & $\Delta(\mathrm{CAL}-\mathrm{SiL})[\% o]$ & $\chi[\mathrm{ppb}]$ \\
& $\delta \mathrm{D}_{\mathrm{V}-\mathrm{SMOW}}[\%$ ] & & \\
\hline CAL1 (He) & $21.1^{*}$ & $121.0 \pm 0.9$ & $2094 \pm 8$ \\
CAL2 (He) & -19 & $80.9 \pm 1.0$ & $1972 \pm 4$ \\
CAL1 & $21.1^{*}$ & $113.5 \pm 1.3$ & $2011 \pm 20$ \\
CAL2 & -19 & $73.7 \pm 1.4$ & $2217 \pm 34$ \\
CAL3 & -164.9 & $-73.0 \pm 1.1$ & $2183 \pm 24$ \\
\hline
\end{tabular}

* Corrected from originally assigned value, see text.

consistent and the calibrations indicate no long-term trends, final appreciation of the absolute precision of the $\delta$-scale is difficult, because of the small range covered by the DC samples used for calibration. It should also be noted that DC are air samples themselves and not well-defined calibration gases.

\subsection{Linearity}

An isotope system is called linear when the measured $\delta$-value is independent of the peak area, i.e., the amount of sample injected, and non-linear if $\delta$-values depend on the peak size. Linearity in this context means, that all involved isotopes are influenced equally according to their original amount, e.g. a $50 \%$ removal of both isotopologues ${ }^{12} \mathrm{CH}_{4}$ and ${ }^{13} \mathrm{CH}_{4}$ does not change $\delta^{13} \mathrm{C}$ compared to its original value. Often this is not the case and non-linearity effects change the $\delta$-value.

One has to differentiate between a $\delta$ shift produced due to sample preparation and possible fractionation caused by the data evaluation algorithm. The first is a physical signal; the second is a mathematical artifact. For example, if the background before the peak is defined inadequately, this usually causes non-linearities even if the sample itself is unchanged (see chapter 3). 
Three methods have been developed to identify and quantify non-linearity effects. The first one is stepwise dilution of a flask containing the reference air (SIL, CAL or DC) with $\mathrm{CH}_{4}$-free air. The second one is partial filling of the sample loop by reducing the filling time. There is an excellent linear correlation between filling time and peak area. This method has the advantage that injected sample amount can be freely varied and it can be fully automated, but it is less accurate than the dilution series. Finally, as HSD retains $\mathrm{CH}_{4}$ for more than $20 \mathrm{~min}$, it is possible to make two consecutive sample injections for the same measurement and thus preconcentrate twice the amount. For low concentration samples, this allows repeating the same analysis with larger peak areas that are less sensitive to the background detection.

Over the past years, the system has been linear for long periods, but also showed non-linearity effects. When a non-linearity has been is observed, it needs to be quantified and a suitable correction has to be applied. However, non-linearities mainly play a role for samples that strongly deviated from $c_{\text {SIL }}$, e.g. upper stratospheric or source-contaminated samples. In most cases the actual nonlinearity effects are negligible for sample sets that cover only a small concentration interval close to $c_{\text {SIL }}$.

\section{Conclusions}

The analytical system described here allows fast, high precision measurements of $\delta \mathrm{D}$ and $\delta^{13} \mathrm{C}$ of atmospheric $\mathrm{CH}_{4}$ samples. Typical reproducibilities of $\pm 0.07 \%$ for $\delta^{13} \mathrm{C}$ and $2.3 \%$ for $\delta \mathrm{D}$ can be reached in routine operation, and also for $\mathrm{CH}_{4}$ concentration a reproducibility of $17 \mathrm{ppb}$ has been reached. Peak integration is a limiting issue for the quality of $\delta \mathrm{D}$ measurements. With the increase in $\mathrm{CH}_{4}$ isotope studies, an international calibration effort is needed and the link calibration of the Utrecht University reference scale to other studies has been described in detail. The sample inlet system with a high pressure inlet for fully automated operation and a low pressure inlet for semi automated operation is very versatile and has already been applied to a large number of different sample sets, including tropospheric air samples, stratospheric air samples, air extracted from polar firn, $\mathrm{CH}_{4}$ from organic matter, $\mathrm{CH}_{4}$ from biomass burning or $\mathrm{CH}_{4}$ extracted from sea water.

Acknowledgements. This work was funded by the Dutch NWO, project number 865.07.001.

Edited by: F. Keppler

\section{References}

Behrens, M., Schmitt, J., Richter, K. U., Bock, M., Richter, U. C., Levin, I., and Fischer, H.: A gas chromatography/combustion/isotope ratio mass spectrometry system for high-precision delta C-13 measurements of atmospheric methane extracted from ice core samples, Rapid Commun. Mass Spectrom., 22, 3261-3269, 2008.

Bergamaschi, P., Schupp, M., and Harris, G. W.: High-precision direct measurements of ${ }^{13} \mathrm{CH}_{4} /{ }^{12} \mathrm{CH}_{4}$ and $\mathrm{CH}_{3} \mathrm{D} /{ }^{12} \mathrm{CH}_{4}$ ratios in atmospheric methane sources by means of a long-path tunable diode laser absorbtion spectrometer, Appl. Opt., 33, No. 33, 7704-7716, 1994.

Bergamaschi, P., Brenninkmeijer, C. A. M., Hahn, M., Röckmann, T., Scharffe, D. H., Crutzen, P. J., Elansky, N. F., Belikov, I. B., Trivett, N. B. A., and Worthy, D. E. J.:: Isotope analysis based source identification for atmospheric $\mathrm{CH}_{4}$ and $\mathrm{CO}$ across Russia using the Trans-Siberian railroad, J. Geophys. Res., D7, 82278235, 1998.

Bergamaschi, P., Bräunlich, M., Marik, T., and Brenninkmeijer, C. A. M.: Measurements of the carbon and hydrogen isotopes of atmospheric methane at Izana, Tenerife: Seasonal cycles and synoptic-scale variations, J. Geophys. Res., 105, 14531-14546, 2000.

Bergamaschi, P., Frankenberg, C., Meirink, J. F., Krol, M., Villani, M. G., Houweling, S., Dentener, F., Dlugokencky, E. J., Miller, J. B., Gatti, L. V., Engel, A., and Levin, I.: Inverse modeling of global and regional $\mathrm{CH} 4$ emissions using SCIAMACHY satellite retrievals, J. Geophys. Res., 114, D22301, doi:22310.21029/22009JD012287, 2009.

Bilke, S. and Mosandl, A.: Measurements by gas chromatography/pyrolysis/mass spectrometry: fundamental conditions in ${ }^{2} \mathrm{H} /{ }^{1} \mathrm{H}$ isotope ratio analysis, Rapid Commun Mass Sp, 16, 2002.

Bock, M., Schmitt, J., Behrens, M., Moller, L., Schneider, R., Sapart, C., and Fischer, H.: A gas chromatography/pyrolysis/isotope ratio mass spectrometry system for highprecision delta D measurements of atmospheric methane extracted from ice cores, Rapid Commun. Mass Spectrom., 24, 621-633, 2010a.

Bock, M., Schmitt, J., Moller, L., Spahni, R., Blunier, T., and Fischer, H.: Hydrogen Isotopes Preclude Marine Hydrate CH4 Emissions at the Onset of Dansgaard-Oeschger Events, Science, 328, 1686-1689, 2010b.

Bräunlich, M., Aballain, O., Marik, T., Jöckel, P., Brenninkmeijer, C. A. M., Chappellaz, J., Barnola, J. M., Mulvaney, R., and Sturges, W. T.: Changes in the global atmospheric methane budget over the last decades inferred from C-13 and D isotopic analysis of Antarctic firn air, J. Geophys. Res., 106, 20465-20481, 2001.

Brenninkmeijer, C. A. M., Janssen, C., Kaiser, J., Röckmann, T., Rhee, T. S., and Assonov, S. S.: Isotope effects in the chemistry of atmospheric trace gases, Chem. Rev., 103, 5125-5162, 2003.

Burgoyne, T. W. and Hayes, J. M.: Quantitative production of H-2 by pyrolysis of gas chromatographic effluents, Anal. Chem., 70, 5136-5141, 1998.

Dentener, F., Peters, W., Krol, M., van Weele, M., Bergamaschi, P., and Lelieveld, J.: Interannual variability and trend of CH4 lifetime as a measure for $\mathrm{OH}$ changes in the 1979-1993 time period, J. Geophys. Res., 108, 4442, doi:4410.1029/2002JD002916, 2003.

Dlugokencky, E. J., Masarie, K. A., Lang, P. M., Steele, P. P., and Nisbet, E. G.: A dramatic decrease in the growth rate of atmospheric methane in the Northern Hemisphere during 1992, Geophys. Res. Lett., 21, 45-48, 1994.

Dlugokencky, E. J., Masarie, K. A., Tans, P. P., Conway, T. J., and 
Xiong, X.: Is the amplitude of the methane seasonal cycle changing?, Atmos. Environ., 31, 21-26, 1997.

Dlugokencky, E. J., Masarie, K. A., Lang, P. M., and Tans, P. P.: Continuing decline in the growth rate of the atmospheric methane burden, Nature, 393, 447-450, 1998.

Dlugokencky, E. J., Walter, B. P., Masarie, K. A., Lang, P. M., and Kasischke, E. S.: Measurements of an anomalous global methane increase during 1998, Geophys. Res. Lett., 28, 499-502, 2001.

Dlugokencky, E. J., Houweling, S., Bruhwiler, L., Masarie, K. A., Lang, P. M., Miller, J. B., and Tans, P. P.: Atmospheric methane levels off: Temporary pause or a new steady-state?, Geophys. Res. Lett., 30, 1992, doi:10.1029/2003GL018126, 2003.

Dlugokencky, E. J., Myers, R. C., Lang, P. M., Masarie, K. A., Crotwell, A. M., Thoning, K. W., Hall, B. D., Elkins, J. W., and Steele, L. P.: Conversion of NOAA atmospheric dry air $\mathrm{CH}_{4}$ mole fractions to a gravimetrically prepared standard scale, J. Geophys. Res., 110, D18306, doi:18310.11029/12005jd006035, 2005.

Dlugokencky, E. J., Bruhwiler, L., White, J. W. C., Emmons, L. K., Novelli, P. C., Montzka, S. A., Masarie, K. A., Lang, P. M., Crotwell, A. M., Miller, J. B., and Gatti, L. V.: Observational constraints on recent increases in the atmospheric CH4 burden, Geophys. Res. Lett., 36, L18803, doi:18810.11029/12009g1039780, 2009.

Etheridge, D. M., Steele, L. P., Francey, R. J., and Langenfelds, R. L.: Atmospheric methane between $1000 \mathrm{AD}$ and present: Evidence of antropogenic emissions and climatic variability, J. Geophys. Res., 103, 15979-15993, 1998.

Ferretti, D., Miller, J., White, J., Etheridge, D., Lassey, K., Lowe, D., Allan, B., MacFarling, C., Dreier, M., Trudinger, C., and Ommen, T. V.: Unexpected changes to the global methane budget over the past 2000 years, Science, 309, 1714-1717, 2005.

Fischer, H., Behrens, M., Bock, M., Richter, U., Schmitt, J., Loulergue, L., Chappellaz, J., Spahni, R., Blunier, T., Leuenberger, M., and Stocker, T. F.: Changing boreal methane sources and constant biomass burning during the last termination, Nature, 452, 864-867, 2008.

Forster, P., Ramaswamy, V., Artaxo, P., Berntsen, T., Betts, R., Fahey, D. W., Haywood, J., Lean, J., Lowe, D. C., Myhre, G., Nganga, J., R. Prinn, Raga, G., Schulz, M., and Dorland, R. V.: Changes in Atmospheric Constituents and in Radiative Forcing, in: Climate Change 2007: The Physical Science Basis. Contribution of Working Group I to the Fourth Assessment Report of the Intergovernmental Panel on Climate Change, edited by: Solomon, S., Qin, D., Manning, M., Chen, Z., Marquis, M., Averyt, K. B., M.Tignor, and Miller, H. L., Cambridge University Press, Cambridge, UK and New York, NY, USA, 2007.

Frankenberg, C., Bergamaschi, P., Butz, A., Houweling, S., Meirink, J. F., Notholt, J., Petersen, A. K., Schrijver, H., Warneke, T., and Aben, I.: Tropical methane emissions: A revised view from SCIAMACHY onboard ENVISAT, Geophys. Res. Lett., 35, L15811, doi:15810.11029/12008g1034300, 2008.

Jackson, S. M., Morgan, G. H., Morse, A. D., Butterworth, A. L., and Pillinger, C. T.: The use of static mass spectrometry to determine the combined stable isotopic composition of small samples of atmospheric methane, Rapid Commun. Mass Spectrom., 13, 1329-1333, 1999.

Karlsdottir, S. and Isaksen, I. S. A.: Changing methane lifetime: Possible cause for reduced growth, Geophys. Res. Lett., 27, 93-
96, 2000.

Keppler, F., Hamilton, J. T. G., Brass, M., and Röckmann, T.: Methane emissions from terrestrial plants under aerobic conditions, Nature, 439, 187-191, doi:110.1038/nature04420, 2006.

Keppler, F., Boros, M., Frankenberg, C., Lelieveld, J., McLeod, A., Pirttila, A. M., Röckmann, T., and Schnitzler, J. P.: Methane formation in aerobic environments, Environmental Chemistry, 6 , 459-465, 2009.

Leckrone, K. J. and Hayes, J. M.: Efficiency and temperature dependence of water removal by membrane dryers, Anal. Chem. 69, 911-918, 1997.

Levin, I., Glatzel-Mattheier, H., Marik, T., Cuntz, M., Schmidt, M., and Worthy, D. E.: Verification of German methane emission inventories and their recent changes based on atmospheric observations, J. Geophys. Res., 104, 3447-3456, 1999.

Lowe, D. C., Brenninkmeijer, C. A. M., Brailsford, G. W., Lassey, K. R., Gomez, A. J., and Nisbet, E. G.: Concentration and ${ }^{13} \mathrm{C}$ Records of Atmospheric Methane in New-Zealand and Antarctica - Evidence for Changes in Methane Sources, J. Geophys. Res., 99, 16913-16925, 1994.

MacFarling Meure, C., Etheridge, D., Trudinger, C., Steele, P., Langenfelds, R., Ommen, T. V., Smith, A., and Elkins, J.: Law Dome $\mathrm{CO}_{2}, \mathrm{CH}_{4}$ and $\mathrm{N}_{2} \mathrm{O}$ ice core records extended to 2000 years BP Geophys. Res. Lett., 33, L14810, doi:14810.11029/12006GL026152 2006.

McLeod, A. R., Fry, S. C., Loake, G. J., Messenger, D. J., Reay, D. S., Smith, K. A., and Yun, B. W.: Ultraviolet radiation drives methane emissions from terrestrial plant pectins, New Phytol., 180, 124-132, 2008.

Meirink, J. F., Bergamaschi, P., Frankenberg, C., d'Amelio, M. T. S., Dlugokencky, E. J., Gatti, L. V., Houweling, S., Miller, J. B., Röckmann, T., Villani, M. G., and Krol, M. C.: Four-dimensional variational data assimilation for inverse modeling of atmospheric methane emissions: Analysis of SCIAMACHY observations, J. Geophys. Res., 113, D17301, doi:17310.11029/12007JD009740, 2008.

Merritt, D. A., Hayes, J. M., and Des Marais, D. J.: Carbon isotopic analysis of atmospheric methane by isotope-ratio-monitoring gas chromatography-mass spectrometry, J. Geophys. Res., 100D, 1317-1326, 1995.

Miller, J. B., Mack, K. A., Dissly, R., White, J. W. C., Dlugokencky, E. J., and Tans, P. P.: Development of analytical methods and measurements of ${ }^{13} \mathrm{C} /{ }^{12} \mathrm{C}$ in atmospheric $\mathrm{CH}_{4}$ from the NOAA/CMDL global air sampling network, J. Geophys. Res., 107, doi:10.1029/2001JD000630, 4178, 2002.

Mischler, J. A., Sowers, T. A., Alley, R. B., Battle, M., McConnell, J. R., Mitchell, L., Popp, T., Sofen, E., and Spencer, M. K.: Carbon and hydrogen isotopic composition of methane over the last 1000 years, Global Biogeochem. Cycles, 23, GB4024, doi:10.1029/2009GB003460, 2009.

Prinn, R. G., Weiss, R. F., Miller, B. R., Huang, J., Alyea, F. N., Cunnold, D. M., Fraser, P. J., Hartley, D. E., and Simmonds, P. G.: Atmospheric trends and lifetime of $\mathrm{CH}_{3} \mathrm{CCI}_{3}$ and global $\mathrm{OH}$ concentrations, Science, 269, 187-192, 1995.

Quay, P., Stutsman, J., Wilbur, D., Snover, A., Dlugokencky, E., and Brown, T.: The isotopic composition of atmospheric methane, Global Biogeochem Cy, 13, 445-461, 1999.

Rasmussen, R. A. and Khalil, M. A. K.: Atmospheric Methane $\left(\mathrm{CH}_{4}\right)$ - Trends and Seasonal Cycles, J. Geophys. Res., 86, 
9826-9832, 1981.

Ricci, M. P., Merrit, D. A., Freeman, K. H., and Hayes, J. M.: Acquisition and processing of data for isotope-ratio-monitoring mass spectrometry, Org. Geochem., 21 No. 6/7, 561-571, 1994.

Rice, A. L., Gotoh, A. A., Ajie, H. O., and Tyler, S. C.: Highprecision continuous-flow measurement of delta $\mathrm{C}-13$ and delta D of atmospheric $\mathrm{CH}_{4}$, Anal. Chem., 73, 4104-4110, 2001.

Santrock, J., Studley, S. A., and Hayes, J. M.: Isotopic analyses based on the mass spectrum of carbon dioxide, Anal. Chem., 57, 1444-1448, 1985.

Schaefer, H., Whiticar, M. J., Brook, E. J., Petrenko, V. V., Ferretti, D., and Severinghaus, J.: Ice Record of $\delta^{13} \mathrm{C}$ for Atmospheric $\mathrm{CH}_{4}$ Across the Younger Dryas-Preboreal Transition, Science, 313, 1109-1112, 2006.

Schaefer, H. and Whiticar, M. J.: Measurement of stable carbon isotope ratios of methane in ice samples, Org. Geochem., 38, 216-226, 2007.

Sessions, A. L., Burgoyne, T. W., and Hayes, J. M.: Determination of the $\mathrm{H}-3$ factor in hydrogen isotope ratio monitoring mass spectrometry, Anal. Chem., 73, 200-207, 2001a.

Sessions, A. L., Burgoyne, T. W., and Hayes, J. M.: Correction of $\mathrm{H}-3(+)$ contributions in hydrogen isotope ratio monitoring mass spectrometry, Anal. Chem., 73, 192-199, 2001b.

Sofer, G. K.: Current Applications of Chromatography in Biotechnology, Bio-Technology, 4, 712-716, 1986a.

Sofer, Z.: Chemistry of Hydrogen Gas Preparation by Pyrolysis for the Measurement of Isotope Ratios in Hydrocarbons, Anal. Chem., 58, 2029-2032, 1986b

Sowers, T., Bernard, S., Aballain, O., Chappellaz, J., Barnola, J. M., and Marik, T.: Records of the delta ${ }^{13} \mathrm{C}$ of atmospheric $\mathrm{CH}_{4}$ over the last 2 centuries as recorded in Antarctic snow and ice, Global Biogeochem Cy, 19, GB2002, doi:2010.1029/2004GB002408, 2005 .
Sowers, T.: Late quaternary atmospheric $\mathrm{CH}_{4}$ isotope record suggests marine clathrates are stable, Science, 311, 838-840, 2006.

Sowers, T.: Atmospheric methane isotope records covering the Holocene period, Quaternary Science Reviews, 29, 213-221, 2010.

Steele, L. P., Dlugokencky, E. J., Lang, P. M., Tans, P. P., Martin, R. C., and Masarie, K. A.: Slowing Down of the Global Accumulation of Atmospheric Methane During the 1980s, Nature, 358, 313-316, 1992.

Tarasova, O. A., Brenninkmeijer, C. A. M., Assonov, S. S., Elansky, N. F., Rckmann, T., and Brass, M.: Atmospheric $\mathrm{CH}_{4}$ along the Trans-Siberian railroad (TROICA) and river Ob: Source identification using stable isotope analysis, Atmos. Environ., 40, 56175628, 2006.

Vigano, I., van Weelden, H., Holzinger, R., Keppler, F., McLeod, A., and Rckmann, T.: Effect of UV radiation and temperature on the emission of methane from plant biomass and structural components, Biogeosciences, 5, 937-947, 2008, http://www.biogeosciences.net/5/937/2008/.

Vigano, I., Röckmann, T., Holzinger, R., van Dijk, A., Keppler F., Greule, M., Brand, W. A., Geilmann, H., and van Weelden, H.: The stable isotope signature of methane emitted from plant material under UV irradiation, Atmos. Environ., 43, 5637-5646, doi:5610.1016/j.atmosenv.2009.5607.5046, 2009.

Vigano, I., Holzinger, R., Keppler, F., Greule, M., Brand, W. A., Geilmann, H., van Weelden, H., and Röckmann, T.: Water drives the deuterium content of the methane emitted from plants, Geochim. Cosmochim. Act., 74, 3865-3873, 2010.

Werner, R. A. and Brand, W. A.: Referencing strategies and techniques in stable isotope ratio analysis, Rapid Commun Mass Sp, $15,501-519,2001$ 